\title{
Editorial: Transplant International Goes for GOLD!
}

\author{
Maria Irene Bellini ${ }^{1}$, Nuria Montserrat ${ }^{2}$, Maarten Naesens ${ }^{2}$, Thomas Neyens ${ }^{3}$, \\ Stefan Schneeberger ${ }^{2}$ and Thierry Berney ${ }^{4 *}$ \\ ${ }^{1}$ Social Media Editor, Transplant International, ${ }^{2}$ Deputy Editor-in-Chief, Transplant International, ${ }^{3}$ Statistical Editor, Transplant \\ International, ${ }^{4}$ Editor-in-Chief, Transplant International
}

Transplant International is starting the New Year with a new publisher. After a rigorous review process, Frontiers Partnerships was considered the best fit four our mission and was selected based on their high quality performance and their enthusiasm for active engagement in our journal $(1,2)$.

One key criterion was our determination to move to a Gold Open Access model. The publication of medical science in open access format has been growing over the past decade, on what is a seemingly irreversible path. Indeed, in 2020, the number of papers published in open access exceeded for the first time those accessible by subscription only (3). We believe that open access publication is part of the dynamic process of open research, which starts with the publication of research in preprint servers while the manuscript undergoes revisions and improvements, and ends with the granting of full access to source data, for the sake of transparency, reproducibility of experiments, and the fostering of more rigorous science. These considerations are embodied in the FAIR guiding principles for scientific data management - Findability, Accessibility, Interoperability, and Reusability- $(4,5)$ to which Transplant International explicitly adheres.

Open access publishing has become a general request from academic institutions to their scholars, but also, and more compellingly, from most funding agencies who require that all scientific outputs resulting from their grants be made freely available to all $(6,7)$. Open access publishing cannot exist without payment of an author publication fee, which may sometimes generate some frustration, but is covered by an increasing number of funding agencies and institutions.

However, there is much more to open access than the ethics of open science, institutional requests or publication costs. The common goal for all stakeholders in the scientific publication process is to disseminate research and increase its overall quality, acknowledgment, visibility and notoriety. Depending on perspective, a variety of metrics are available. They are useful benchmarking indicators, designed to measure different types of impact. Although often confused, they are not interchangeable. The Impact Factor (IF) is an indicator of where a specific journal is standing in the landscape of scientific titles, but not of a particular article or author. Usage metrics for articles (downloads, views, engagements and captures) or the h-index for authors were designed for this purpose (8). Most of these metrics are driven by citations in the scientific literature and will increase through a higher rate of citations.

Evidence indicates that open access publication confers a citation advantage, at least in selected fields of medical science (9-13). The citation advantage is beneficial to all parties involved, and in particular the authors, but also the academic institutions (14) and the journal $(15,16)$.

Social media have emerged to a leading position among the tools of fast dissemination of scientific output $(17,18)$. They are widely used for this purpose by investigators, but also by social media editors of scientific journals (18). Alternative metric scores (such as Altmetric or PlumX) comprehensively assess usage, captures, mentions, social media posts and citations, but also new categories -such as clinical or policy citations, news articles or mentions, blog posts, comments, reviews or links-that indicate active engagement and repetitive interactions with the public (8). They give an interesting idea of the immediate "social" attention gained by a particular scientific publication, as opposed to the 
h-index which takes years to build for a particular author (8). They measure its impact in the web community, and very often positively influence its future citations (13). There is in fact growing evidence for a link between citations, altmetric scores and open access, at least in certain fields of biomedical research (18-20).

Transplant International is starting this year with a lot of ambitions $(1,2)$, that we believe will be better served by our choice to go for gold. We are confident that our readership, but also the authors submitting their valuable work to Transplant International, will embrace this choice and, as we thank you for your trust, we offer you our best wishes for a successful 2022. Happy New Year !

\section{REFERENCES}

1. Berney T, Montserrat N, Naesens M, Schneeberger S, Bellini MI, Neyens T. Editorial: Changing of the Guard at Transplant International. Transpl Int (2021) 34:609. doi:10.1111/tri.13843

2. Berney T, Bellini MI, Montserrat N, Naesens M, Neyens T, Schneeberger S. Transplant International: A New Beginning. Transpl Int (2021) 34:1586-7. doi:10.1111/tri.13994

3. Hook D. Open Access Surpasses Subscription Publication Globally for the First Time (2021). Available at: https://www.dimensions.ai/blog/open-accesssurpasses-subscription-publication-globally-for-the-first-time/ (Accessed Dec 20, 2021).

4. Europa (2021). Available at: https://ec.europa.eu/info/sites/default/files/ turning_fair_into_reality_0.pdf (Accessed Dec 31, 2021).

5. Wilkinson MD, Dumontier M, Aalbersberg IJ, Appleton G, Axton M, Baak A, et al. The FAIR Guiding Principles for Scientific Data Management and Stewardship. Sci Data (2016) 3:160018. doi:10.1038/sdata.2016.18

6. Europa (2020). Available at: https://ec.europa.eu/info/research-andinnovation/strategy/strategy-2020-2024/our-digital-future/open-science/ open-access_en (Accessed Dec 31, 2021).

7. Grants (2021). Available at: https:/grants.nih.gov/grants/policy/nihgps/ html5/section_8/8.2.2_nih_public_access_policy.htm (Accessed Dec 31, 2021).

8. Kavic MS, Satava RM. Scientific Literature and Evaluation Metrics: Impact Factor, Usage Metrics, and Altmetrics. JSLS (2021) 25(3):e2021.00010. doi:10. 4293/JSLS.2021.00010

9. Basson I, Blanckenberg JP, Prozesky H. Do open Access Journal Articles Experience a Citation Advantage? Results and Methodological Reflections of an Application of Multiple Measures to an Analysis by WoS Subject Areas. Scientometrics (2021) 126:459-84. doi:10.1007/s11192-02003734-9

10. Zhang G, Wang Y, Xie W, Du H, Jiang C, Wang X. The Open Access Usage Advantage: A Temporal and Spatial Analysis. Scientometrics (2021) 126: 6187-99. doi:10.1007/s11192-020-03836-4

11. Patel RB, Vaduganathan M, Mosarla RC, Venkateswaran RV, Bhatt DL, Bonow RO. Open Access Publishing and Subsequent Citations Among Articles in Major Cardiovascular Journals. Am J Med (2019) 132:1103-5. doi:10.1016/j.amjmed.2019.02.009

\section{AUTHOR CONTRIBUTIONS}

All authors listed have made a substantial, direct, and intellectual contribution to the work and approved it for publication.

\section{CONFLICT OF INTEREST}

The authors declare that the research was conducted in the absence of any commercial or financial relationships that could be construed as a potential conflict of interest.

12. Alkhawtani RHM, Kwee TC, Kwee RM. Citation Advantage for Open Access Articles in European Radiology. Eur Radiol (2020) 30:482-6. doi:10.1007/ s00330-019-06389-0

13. Curno M, Oeben S. Scientific Excellence at Scale: Open Access Journals Have a clear Citation Advantage over Subscription Journals (2018). Available at: https://blog.frontiersin.org/2018/07/11/scientific-excellence-at-scale-open-accessjournals-have-a-clear-citation-advantage-over-subscription-journals/ (Accessed Jan 1, 2022).

14. Blair L, Odell J. The Open Access Policy Citation Advantage for a Medical School (2020). Available at: https://scholarworks.iupui.edu/bitstream/handle/1805/ 24076/Blair-Odell-2020-OAPCA-MedicalSchool.pdf? sequence $=1$ \&isAllowed $=y$ (Accessed Dec 20, 2021).

15. Bautista-Puig N, Lopez-Illescas C, de Moya-Anegon F, Guerrero-Bote V, Moed HF. Do journals Flipping to Gold Open Access Show an OA Citation or Publication Advantage? Scientometrics (2020) 124:2551-75. doi:10.1007/s11192-020-03546-x

16. AlRyalat SA, Saleh M, Alaqraa M, Alfukaha A, Alkayed Y, Abaza M, et al. The Impact of the Open-Access Status on Journal Indices: A Review of Medical Journals. F1000Res (2019) 8:266. doi:10.12688/f1000research.17979.1

17. Bellini MI, Montserrat N, Naesens M, Neyens T, Schneeberger S, Berney T. The Power of Online Tools for Dissemination: Social media, Visual Abstract, and beyond. Transpl Int (2021) 34:1174-6. doi:10.1111/tri.13929

18. Clayson PE, Baldwin SA, Larson MJ. The Open Access Advantage for Studies of Human Electrophysiology: Impact on Citations and Altmetrics. Int J Psychophysiology (2021) 164:103-11. doi:10.1016/j.ijpsycho.2021.03.006

19. Thelwall M, Haustein S, Larivière V, Sugimoto CR. Do altmetrics Work? Twitter and Ten Other Social Web Services. PLoS One (2013) 8:e64841. doi:10. 1371/journal.pone.0064841

20. Wang X, Liu C, Mao W, Fang Z. The Open Access Advantage Considering Citation, Article Usage and Social media Attention. Scientometrics (2015) 103: 555-64. doi:10.1007/s11192-015-1547-0

Copyright (C) 2022 Bellini, Montserrat, Naesens, Neyens, Schneeberger and Berney. This is an open-access article distributed under the terms of the Creative Commons Attribution License (CC BY). The use, distribution or reproduction in other forums is permitted, provided the original author(s) and the copyright owner(s) are credited and that the original publication in this journal is cited, in accordance with accepted academic practice. No use, distribution or reproduction is permitted which does not comply with these terms. 